\title{
La yihad sunita del Estado Islámico y Al-Qaeda: islamismo, antiimperialismo... ¿y nihilismo político-mesiánico?*
}

\author{
The Sunni Jihad of the Islamic State and \\ Al-Qaeda: Islamism, anti-imperialism... \\ and political-messianic nihilism?
}

\author{
Cristóbal Ortiz** \\ Isaac Caro***
}

\begin{abstract}
Resumen
El presente artículo abordará el yihadismo sunita, específicamente los casos de Al-Qaeda y el Estado Islámico. También se destaca su antiimperialismo, como grupos de resistencia contra Occidente, cuna del capitalismo que mundializa los patrones culturales que provocan la pérdida de identidad islámica en un mundo sin alternativas metafísicas. Se propone una tercera mirada, enfocada en el aspecto nihilista político. Nihilista porque pretende destruir la civilización occidental y todo aquel que se oponga a su visión, sea o no musulmán. Esto
\end{abstract}

\footnotetext{
Este artículo forma parte del Proyecto Fondecyt No 1150057.

" Cientista político, Licenciado en Ciencia Política y Relaciones Internacionales, Universidad Alberto Hurtado. Asistente de investigación en proyecto de Centro Democracia y Comunidad (CDC). Email: cortizw@gmail.com. Recibido: 3 de mayo de 2016 (original); 21 de marzo de 2017 (modificaciones). Aceptado: 3 de abril de 2017.

**** Doctor en Estudios Americanos, Universidad de Santiago de Chile. Profesor titular Departamento de Ciencia Política y Relaciones Internacionales, Universidad Alberto Hurtado.Email: icaro@uahurtado.cl
} 
se comprobará al examinar el contexto político de origen de ambos grupos, las biografías de sus líderes y sus discursos para ver a qué nivel se reflejan el islamismo, el antiimperialismo y/o el nihilismo político.

Palabras clave: Nihilismo político - antiimperialismo - fundamentalismo religioso - mesianismo político - Al-Qaeda, Estado Islámico.

\section{Abstract}

This article will address the Sunni Jihadism, specifically the cases of Al-Qaeda and the Islamic State. It is also worth highlighting its anti-imperialism, as resistance groups against the West, the cradle of capitalism which globalizes cultural patterns that cause loss of Islamic identity in a world without metaphysical alternatives. A third gaze is proposed, focused in the political nihilistic aspect. Nihilistic because it seeks to destroy Western civilization and anyone who opposes their vision, whether Muslim or not. This shall be verified by examining the political context of the origin of both groups, the biographies of their leaders and their speeches, to see in what level are reflected the fundamentalism, anti-imperialism and / or political nihilism.

Keywords: Political nihilism - anti-imperialism - religious fundamentalism - political messianism - Al-Qaeda - Islamic State. 


\section{INTRODUCCIÓN}

La literatura especializada sobre islamismo radical, fundamentalismo islámico, islam político (Caro, 2002; Bofill, 2011; Izquierdo, 2011; Ahmed, 2012; Valenzuela, 2012; Alonso, 2015), destaca el antioccidentalismo de estos movimientos porque atacan símbolos occidentales -como el World Trade Center-, a la par que declaran la "guerra santa" en contra de Occidente, buscando la "victoria de la fe islámica" (Bofill, 2011). Esto explicaría los atentados en Estados Unidos y Europa (Nueva York, 2001; Madrid, 2003; Londres, 2005; París, 2015; Bruselas, 2016). Su objetivo sería imponer la ley islámica (sharia) en los órdenes político, económico y cultural. Para ellos, el imperialismo es occidental porque de ahí surge el sistema capitalista que, trascendiendo lo religioso, afecta los patrones de comportamiento social, político y económico en culturas distintas. Por tanto, estos movimientos yihadistas surgirían por el deseo de reafirmar su identidad cultural -determinado por la diada diferenciadora del "nosotros/ellos" - frente a la amenaza extranjera. Por otro lado, el antiimperialismo, en concreto, se manifiesta en un odio hacia las potencias extranjeras (países europeos más Estados Unidos), las cuales se perciben como culpables de los problemas políticos, sociales y económicos, en tanto sus interven- ciones políticas y militares dentro de Medio Oriente han generado un contexto de inestabilidad, violencia y pobreza.

Acá se propone una nueva categoría de estudio de dicho fenómeno: nihilismo político-mesiánico. Sería tal no porque busquen, literalmente, la nada -significado etimológico de nihilismo-, sino porque, como actor político, buscan destruir lo establecido -de ahí su violencia contra Occidente- para imponer otro régimen político. Por lo mismo, el foco está no solo en el aspecto político, sino también en el religioso. Este último sería la razón legitimadora para la consecución de objetivos de poder de la yihad. Este tipo de nihilismo tiene su base en los métodos de acción política, más que en los fines valóricos que quieren establecer, y tiene una estrecha relación con el mesianismo político, pues el fin, en este caso el califato, es concebido como el "paraíso terrenal" al que nadie debe oponerse, y en el que cualquier medio, aunque sea violento o destructivo, se justifica en nombre de ese fin.

De esa manera, en este trabajo se busca responder si la yihad sunita global, enfocada a los casos de AlQaeda y el Estado Islámico (EI), representan -en efecto- lo que se definirá como nihilismo político, siendo esta una tercera forma de definir el fenómeno, sumándose a los conceptos de fundamentalismo religioso y antiimperialismo. Estas 
tres miradas sobre la yihad sunita global no necesariamente han de ser excluyentes entre sí. Al contrario, se estima que son complementarias. Pero la distinción es adecuada para simplificar la explicación.

Este trabajo presentará la revisión y posterior discusión bibliográfica de lo escrito sobre los conceptos centrales: antiimperialismo, fundamentalismo religioso/islamismo y nihilismo político. Este último concepto es el que mayores dificultades presenta. Primero, porque es el concepto novedoso que se propone en este trabajo para estudiar la yihad global sunita. Esto requiere, primero, una justificación teórica y, posteriormente, una comprobación empírica. Una dificultad en este proceso será dar una definición de "nihilismo político-mesiánico". En especial porque sobre nihilismo político se ha reflexionado durante siglos, por lo cual se deberá precisar su significado en el contexto de la yihad sunita global. Para ello nos basaremos en el pensamiento de Nietzsche y en el de quienes han trabajado en torno al mismo. También se considerará la visión de Leo Strauss, quien desarrolla el concepto a partir del nazismo alemán.

Sobre el análisis de los casos de Al-Qaeda y el Estado Islámico (EI), este se hará a partir de la revisión de literatura y prensa especializada para contextualizar sus orígenes políticos. Asimismo, se dará cuenta de los discursos, biografías y nivel de educación de sus líderes principales: Osama Bin Laden y Ayman al-Zawahiri para Al-Qaeda, y Abu Bakr al-Baghdadi para el EI. Ello será importante porque son la cara visible de estos grupos, por lo cual tras ellos se expresa la motivación para la acción radical. Se analizarán entre dos y tres discursos de cada uno de ellos, usando el programa Word Cloud ${ }^{1}$, que jerarquiza de mayor a menor el número de palabras que más se repite en un discurso. Lo anterior, además de establecer similitudes y diferencias entre los casos, permitirá responder la pregunta y comprobar si la realidad empírica de estos casos se condice con la teoría e hipótesis planteadas. Ahora bien, existe conciencia de las limitaciones del programa Word Cloud. Difícilmente un discurso está definido solo por la cantidad de palabras que se repiten. Muchos discursos se destacan por lo que dicen y no por cuántas veces lo dicen. Pero será útil a la hora de considerar los distintos énfasis de cada uno de los líderes al dirigirse a sus militantes -a quienes motivan a la acción- y al mundo entero.

La metodología de este trabajo es eminentemente cualitativa, basada en estudios de caso a través de la recopilación de información de tipo secundario. El estudio de caso es una estrategia de investigación basada en el estudio empírico de uno

1 http://worditout.com/word-cloud/ make-a-new-one 
o pocos casos, con el fin de analizar la configuración de cada uno de ellos para aclarar las características de una clase mayor de fenómenos (similares), mediante el desarrollo y la evaluación de explicaciones teóricas. Así, las conclusiones sobre Al-Qaeda y el Estado Islámico que aquí tengamos, podrán extrapolarse a otros movimientos de la yihad sunita global. Es importante considerar que se rechazó analizar el caso del Talibán, movimiento sunita radical, porque a diferencia de los otros dos casos no pregona la guerra global, sino local -se enfoca en países árabes y musulmanes-. Nuestro mayor interés por la yihad global se da porque el impacto internacional de grupos como Al-Qaeda y el Estado Islámico es mayor que el del Talibán -sin menospreciar las consecuencias de sus acciones- $y$, por otro lado, se debe al hecho de que la yihad global es en apariencia más nihilista, ya que pretende destruir una cultura o civilización entera. Este artículo busca identificar ciertos elementos políticamente nihilistas y mesiánicos en los discursos analizados, tratando de encontrar un porcentaje similar entre palabras o referencias religiosas, antiimperialistas y/o nihilistas.

Nuestra hipótesis sostiene que estos grupos buscan negar y destruir la realidad sociopolítica del mundo contemporáneo, más allá de las reivindicaciones religiosas y antioccidentales. Esto significa que, si los discursos de cada líder mencionado hacen referencia a situaciones o elementos propiamente políticos, se podría decir que existe un componente nihilista y mesiánico en la yihad sunita global. En consecuencia, existe una dicotomía entre el discurso y la práctica: aunque en el discurso difícilmente se encuentren palabras o frases explícitamente nihilistas, el proyecto político de estos grupos busca cambiar de manera radical, violenta y destructiva la sociedad contemporánea. Este artículo está estructurado en cuatro partes. En las tres primeras se verá toda la discusión bibliográfica y teórica respecto de los conceptos de fundamentalismo religioso/ islamismo, antiimperialismo y nihilismo político, respectivamente, $y$ su pertinencia-eminentemente teórica- para definir a la yihad sunita global. Y en un último apartado se relatará parte de la biografía de los líderes (Bin Laden, al-Zawahiri y al-Baghdadi), sus niveles de estudio, además del mencionado análisis de sus discursos.

\section{ISLAMISMO, YIHADISMO, FUNDAMENTALISMO}

Es importante precisar, antes que todo, el concepto de yihad. Este no significa, necesariamente, guerra contra los enemigos del islam; que para la yihad sunita serían los opositores a su visión, sean o no musulmanes. Esa es, como bien expresa 
Gutiérrez (2009), la yihad menor. También hay una yihad mayor, que implica una lucha espiritual "contra la bestia que todo ser humano alberga en su interior" (p. 202). En ese sentido, debe quedar claro que cuando se habla de movimiento yihadista, hablamos de quienes pregonan la yihad menor, que son una gran minoría dentro del islam (Caro, 2002).

Los movimientos yihadistas sunitas son islamismos radicales que buscan imponer la sharia -la ley religiosa islámica- y el califato global, siguiendo una interpretación religiosa de la sociedad mundial, pretendiendo controlar la vida pública y privada de las personas. Sin embargo, la gran mayoría del mundo musulmán es más flexible y pluralista en cuanto a creencias religiosas se refiere (Bofill, 2011). Es necesario diferenciar entre islam -que constituye una religión, una cultura y una civilización que ha hecho una contribución sustantiva a la humanidad-e islamismo -que son movimientos que surgen al interior del islam, que buscan unir la religión y la política-. También se debe dejar en claro que este trabajo tratará de grupos sunitas radicales, como Al Qaeda y el Estado Islámico, dejando fuera la corriente chiíta, cuyo máximo exponente histórico contemporáneo ha sido Irán, siendo relevante también el grupo Hezbollah.
A modo de contexto para el análisis internacional, se debe comprender estos fenómenos de radicalización sunita como parte de lo que Samuel Huntington (1996) denominó "Choque de civilizaciones". Esta fue la respuesta que lanzó dicho autor a la tesis del "fin de la historia", de Francis Fukuyama, quien consideraba que en el mundo de post Guerra Fría no habría conflictos, o se limitarían a pequeñas escaramuzas entre países subdesarrollados (Campuzano, 2007; Caro, 2013). Para Huntington no había fin de la historia. Por el contrario, el conflicto aún está presente en las relaciones internacionales, solo que cambió. Ya no es la ideología lo que motiva al enfrentamiento, sino que son las diferencias culturales y civilizacionales. Así es como define una serie de civilizaciones, donde entre otras están la occidental y la islámica. Huntington supone que cada civilización, si bien tiene diferencias internas, suele actuar unitariamente, y que los conflictos importantes son intercivilizacionales y no intracivilizacionales. Sobre este último punto han surgido críticas al paradigma del "choque de civilizaciones" (Serrano, J. P., 2003; Ferrando, 2005; León, 2008; Caro, 2013), las cuales aducen que el conflicto suele darse dentro de las civilizaciones, no entre estas -esto sería cierto para la yihad, que más daño ha hecho en Medio Oriente que en otra civilización-. 
Aun así, el paradigma del "choque de civilizaciones" sigue siendo útil para explicar el aspecto global de la yihad-sunita.

Tanto Al-Qaeda como el Estado Islámico corresponden a un yihadismo global. Podemos distinguir tres grandes contextos del yihadismo: interno, externo y mundial. El primero es aquel que tiene lugar en contra de regímenes musulmanes que se consideran usurpadores o ilegítimos. Es el caso del Frente Islámico de Salvación en Argelia o de los Hermanos Musulmanes en Egipto. El segundo se caracteriza porque la yihad es contra regímenes de ocupación, como lo muestra el caso de Hamas en Palestina, de los movimientos chechenos en Rusia e islamistas en la zona de Cachemira, India. En el caso de la yihad global, se trata de una guerra santa que tiene como espacio todo el planeta, donde se busca combatir a los infieles, hasta la conversión total de la humanidad al islam (International Crisis Group, 2005).

En este trabajo hacemos una distinción entre fundamentalismo religioso e islamismo o islam político, estos dos últimos más enfocados en el aspecto político-ideológico que en el religioso. El primero surge en el ámbito del evangelicalismo norteamericano para designar corrientes y movimientos que son contrarios a la modernidad y buscan volver a las fuentes originales, con una lectura literal de los textos sagrados. Muchos fundamentalismos no tienen pretensiones de llegar al poder -al menos directamente-, limitando su actividad a sectores sociales específicos, a una ruptura con la vida cotidiana, donde lo central es el cambio en las costumbres y el uso de vestimenta. En el caso de Al-Qaeda y el Estado Islámico, se trata de un islamismo jihadista global, que pretende combatir a Occidente en todos los planos y que busca aplicar la sharia como la principal ley política y religiosa a nivel mundial.

\subsection{Origen y breve historia de Al-Qaeda y el Estado Islámico}

El surgimiento de Al-Qaeda se dio a fines de la década de los setenta, con la invasión de la Unión Soviética en Afganistán, hecho que generó gran indignación en un porcentaje alto de islamistas radicales quienes, organizados por Osama Bin Laden y la CIA estadounidense -en contexto de Guerra Fría-, lograron vencer a las tropas soviéticas (Landau, 2001; Aguirre, 2011; Zarrouk, 2011; Valenzuela, 2012). Una vez ganada la guerra, Estados Unidos dejó de otorgar su generosa ayuda. Esto aumentó el sentido de abandono por parte de la población, porque muchos de esos países estaban en una situación de alta inestabilidad y violencia. Esto lo aprovecharon los muyahidines -los combatientes islamistas radica- 
les- que, con cierto apoyo popular, tomaron el poder en Afganistán (Zarrouk, 2011).

En la guerra contra los soviéticos, Al-Qaeda -que literalmente significa "la base" - era el lugar donde se registraban y entrenaban los muyahidines. Todo era financiado por Osama Bin Laden. Una vez finalizada la guerra, se expandió por otros países de la región, como Pakistán, Sudán y Yemen, entre otros, conformando las llamadas células dependientes de esa base central (Landau, 2001; Aguirre, 2011; Valenzuela, 2012). Ya en ese entonces, entrada la década de los noventa, Estados Unidos era su enemigo número uno.

La ideología de Al-Qaeda se inserta en el salafismo-wahabismo, que justamente busca la instauración del califato y la aplicación literal de la sharia (Aguirre, 2011). Está a favor de la yihad menor contra la yahiliya, que sería la contraparte de la umma o comunidad islámica determinada por la fe, compuesta por los ignorantes que no respetan el islam en su integridad, incluyendo musulmanes (Gutiérrez, 2009; Aguirre, 2011). Por ello, muchos ataques terroristas son dirigidos contra los "gobiernos apóstatas" del Medio Oriente, que han "traicionado al islam", esto incluye gobiernos chiitas, como Irán, y países aliados de Estados Unidos, como Arabia Saudita -donde nació
Osama Bin Laden- (Romero y Troyano, 2013).

En cuanto a su estructuración, Al-Qaeda está conformado por células con base local, las que tienen cierta libertad operativa; mas no ideológica. No obstante, su estructura es muy jerarquizada (Aguirre, 2011). Justamente, es su descentralización operativa -según Ahmed (2012) - la cual le ha permitido mantener su posición sin desintegrarse en una lucha descarnada por un esperable vacío de poder producido con la muerte de Osama Bin Laden, bajo el liderazgo de Ayman al-Zawahiri. Pero también esta fuerte jerarquía y descentralización hace que el alcance de este movimiento sea menos popular, en consideración a que el contacto entre militante y líder es menos directo. No obstante, el rol del liderazgo es fundamental, ya que este cohesiona a las distintas células mediante la propagación de la ideología, la cual es adaptada según las distintas realidades locales.

Los orígenes del Estado Islámico se remontan al año 2003 (Pérez, 2014; Priego, 2014). Su nacimiento se dio en Irak, tras la invasión estadounidense que derrocó al gobierno de Saddam Hussein y eliminó toda influencia de su administración, provocando una fuerte inestabilidad institucional (Corral, 2015). Bajo ese contexto, el Estado Islámico se conformó para expulsar la presencia extranjera del terri- 
torio iraquí (Pérez, 2014; Priego, 2014; Corral, 2015). Sus milicias se mantuvieron después de la guerra, pasando a ser la insurrección sunní contra el gobierno chiita de facto que reemplazó al partido Baaz de Hussein (Corral, 2015). En 2004, el líder del movimiento, en ese entonces Abu Musab al-Zarqawi, juró lealtad a Osama Bin Laden, siendo la célula de Al-Qaeda en Irak. Pero entre 2013 y 2014, con al-Baghdadi como líder, el Estado Islámico decide llevar tropas a Siria para combatir al gobierno represivo de Bashar al-Asad, aluita -corriente del chiismo-, en el contexto de guerra civil post Primavera Árabe. A lo anterior se debe agregar el hecho de que Siria e Irán tienen una alianza militar que ha significado apoyo del segundo al primero para enfrentar a las milicias rebeldes, entre ellas el Frente Al-Nusra, filial de Al-Qaeda, y el EI. Este último pretendió absorber al Frente Al-Nusra, pero Al-Zawahiri apoyó a los primeros, instando a la disolución del Estado Islámico (Priego, 2014), lo cual provocó que este se separase de AlQaeda (Pérez, 2014), funcionando autónomamente sin problemas, gracias al control administrativo que poseían en varias ciudades iraquíes (Pérez, 2014).

Hay quienes han destacado el hecho de que el EI en efecto funciona como un Estado (Priego, 2014; Nadal, 2015). Tiene una administración muy jerarquizada y centralizada (Priego, 2014) -lo cual genera una mayor cercanía líder y militante-, y presenta un cuerpo militar y policial que obliga a cumplir las leyes en los territorios que domina. También ha generado una serie de aparatos burocráticos de bienes y servicios que le ha permitido tener una base de apoyo social relevante (Nadal, 2015). Gran parte de ello se debe a la inmensa cantidad de recursos que posee, obtenidos por medio de los secuestros, venta de armas, petróleo y gasolina, narcotráfico y, por último, financiamiento externo desde países árabes (Priego, 2014). Al día de hoy, el Estado Islámico ha logrado anexarse gran parte del territorio norte de Irak y Siria, representando una amenaza en la frontera occidental de Irán y en el sur de Turquía, países que están respondiendo militarmente contra esta amenaza (Nadal, 2015).

\section{LA EXPRESIÓN}

ANTIIMPERIALISTA

Se puede aducir que el antiimperialismo yihadista es anticapitalista y antioccidental -entendiendo que de ahí nace el sistema capitalista-. Tal rechazo surge en quienes no pertenecen a la región occidental o se sienten alejados de sus costumbres y prácticas. Por ello es que muchos musulmanes entran a la yihad sunita para combatir a los Estados occidentales, en tanto ven peligrar sus patrones culturales y 
religiosos, que le han otorgado a sus sociedades un sentido de pertenencia e identidad, definida en gran parte por la díada nosotros/ ellos, la cual peligra por la "igualación" cultural que el imperialismo occidental traería consigo (Castells, 1999; Caro, 2002; Maalouf, 2005; Romero y Troyano, 2013). Así, la yihad se contrapone a Occidente porque no es capaz de convivir con sus principios civilizatorios (Caro, 2002).

El conflicto geopolítico entre el islam y occidente (mundo cristiano) se remonta a los orígenes mismos del islam, porque se trata de dos sistemas religiosos y políticos mundiales que buscan la hegemonía. En una primera etapa, desde el siglo VII hasta el siglo XVI, el islam estaba en apogeo, llegando a extenderse desde la India hasta los Pirineos. Sin embargo, esta situación se invierte a partir del siglo XVI, con el auge de los imperios coloniales europeos, alcanzando un punto cúlmine con la llegada de Napoleón a Egipto y Siria, a principios del siglo XIX, y luego con el reparto secreto del Medio Oriente entre Francia y Gran Bretaña, mediante los acuerdos Sykes-Picot (1916), una vez producida la desintegración del Imperio turco otomano. Durante todo el siglo XX, entre los componentes de la posición antioccidental, y más especialmente antinorteamericana, que predominaron en el mundo musulmán, estaban ciertas influen- cias intelectuales provenientes de Europa. Una de estas venía de Alemania, donde una visión negativa de Estados Unidos formaba parte de una escuela de pensamiento que incluía a escritores tan diversos como Rainer Maria Rilke, Ernst Jünger y Martin Heidegger. En esta percepción se veía a dicho país como el último ejemplo de civilización sin cultura: rico y confortable; materialmente avanzado; pero desalmado y artificial. Tras el colapso alemán, otra filosofía, aún más antinorteamericana, tomó su lugar, la versión soviética del marxismo, con una denuncia del capitalismo occidental y norteamericano. Más tarde, tomaría su lugar "la nueva mística del tercermundismo": lo que ganó apoyo a estas ideologías en el mundo islámico fue que se oponían a Occidente en su totalidad. Además de lo anterior, la causa más frecuentemente aducida para el sentimiento antioccidental de los musulmanes es el apoyo norteamericano y europeo a Israel (Lewis, 1990). De este modo, el componente antioccidental se ve complementado con un componente antisemita y antisionista, en donde se proclama la destrucción del Estado de Israel, al tiempo que los judíos son vistos como usurpadores de Palestina y particularmente de Jerusalén, la tercera ciudad sagrada para el islam.

El antioccidentalismo del mundo islámico tiene como uno de 
sus principales componentes una denuncia del imperialismo. Lo que se considera inaceptable es la dominación de los infieles sobre verdaderos creyentes. Ahora bien, si se define el imperialismo como la invasión y dominación de países musulmanes por no musulmanes, ¿por qué la hostilidad ha sido mayor hacia Europa occidental que hacia Rusia, la cual gobierna sobre millones de musulmanes? ¿Y por qué incluye a Estados Unidos que nunca ha gobernado una población musulmana, a excepción de un breve interludio en el área de minoría musulmana de Filipinas? Lewis sostiene que "después de todo, los grandes cambios sociales, intelectuales y económicos que han transformado la mayoría del mundo islámico, y dado ascenso a los tan comúnmente denunciados demonios occidentales, como el consumismo y el secularismo, emergieron del Occidente, no de la Unión Soviética” (p. 56). Es el capitalismo occidental y la democracia -y no el secularismo soviético- lo que "provee una auténtica y atractiva alternativa a las formas tradicionales de pensamiento y vida. Los líderes fundamentalistas no están equivocados en ver en la civilización occidental el mayor desafío a la forma de vida que ellos desean retener o restaurar para su pueblo. Además, Estados Unidos es el legítimo heredero de la civilización europea y el líder indiscutible de Occidente, y como tal ha heredado el foco de odio e ira del mundo islámico" (Lewis, 1990).

El surgimiento de Al-Qaeda y el Estado Islámico se da en contextos donde Rusia (Unión Soviética) y/o Estados Unidos intervienen política y militarmente sobre países del Medio Oriente, con un rechazo explícito a las fronteras impuestas por las potencias coloniales a través del pacto secreto Sykes-Picot. Además, hay un rechazo por el apoyo de estas potencias a gobiernos incapaces de solucionar los problemas sociales y políticos (Estados Fallidos), como la brutal desigualdad y la inestabilidad política, realidades presentes pese de que cuentan con petróleo. De hecho, ven que gran parte de esas ganancias la obtienen esas potencias mundiales y algunos pocos grupos de élite internos, lo cual aumenta el descontento y da pie a la radicalización islámica (Izquierdo, 2011; Romero y Troyano, 2013). Así ocurrió en Iraq, Afganistán, Siria y Libia, donde se insertan ambos grupos.

No hay duda que el yihadismo sunita es antiimperialista. Su radical y violento rechazo hacia la civilización occidental, destruyendo símbolos del consumo como el World Trade Center, lo comprueban. Pero no sería válido por sí solo para explicar el fenómeno. Los movimientos antiimperialistas pueden ser pacíficos. Ergo, si bien la yihad sunita es antiimperialista, 
ello no termina de definirla por completo, por lo cual es fundamental considerar el fundamentalismo religioso, y posiblemente, también lo que definimos como nihilismo político-mesiánico.

\section{LA CONTROVERSIA SOBRE SU DIMENSIÓN NIHILISTA}

Es obvio suponer que el islamismo no fundamentalista tampoco es nihilista, ya que no pretende destruir lo establecido, sino cambiar la realidad mediante reformas. Pero tampoco el islamismo fundamentalista lo es necesariamente. Es posible que un grupo interprete literalmente la sharia; que busque alcanzar el poder, sin hacer uso de la violencia. El islamismo fundamentalista pasa a ser nihilista cuando niega lo establecido, niega otras culturas o civilizaciones, y busca su destrucción convocando a la yihad menor. Nihilismo proviene del ruso y significa "desear la nada”. Entonces, nihilismo político en su acepción literal significa apolítica. Este concepto definido y desglosado por Nietzsche (1972; 1981) -sobre el que han reflexionado otros intelectuales (Muñoz, 1994; Ward, 2002; de la Vega, 2006; García, 2008)-, significa el fin de la metafísica, de los horizontes que incentivan a la acción política. Ello se debe al descubrimiento de que en esa pretensión de fin último no existía una realidad objetiva, sino que se escondía la voluntad de poder de otro(s). Así, para Nietzsche hay un nihilismo pasivo, que ocurre cuando el ser humano se da cuenta de la inexistencia de la metafísica, que pasa a ser nihilismo activo cuando consciente de la inexistencia de valores objetivos, es capaz de imponer otros nuevos, superiores a los anteriores, sin negar que son producto de su voluntad de poder, convirtiéndose así en "súper hombre".

En ese punto pareciera ser erróneo definir la yihad sunita como un caso de nihilismo político. Primero, no puede ser pasivo porque sí hay un fin metafísico: el califato y la sharia. Segundo, tampoco sería activo, ya que no hay conciencia, aparentemente, de que los valores que buscan imponer no serían más que obra de su voluntad de poder. Al contrario, todos sus actos lo justifican en nombre de la religión. Pero se debe matizar este punto. Primero, porque, como destaca Valenzuela (2012), “el islamismo (yihadista) se sirve, por cierto, del fundamentalismo, pero opera con la religión de un modo selectivo, no vacilando en violar los 'mandatos de Dios' si es que alguno se opone a sus objetivos de poder” (p. 43). $\mathrm{Su}$ interés es político: instaurar el califato. No dudan en romper los preceptos de su religión con tal de lograrlo. Es decir, niegan su moral religiosa, creen estar por sobre esta (se niegan a sí mismo 
como seres morales y religiosos), a pesar de que la usan para justificar sus actos. Cabe agregar que para Nietzsche, el nihilismo "alcanza su máximo de fuerza relativa como potencia violenta de destrucción: como nihilismo activo" (Nietzsche, 1981: 41). Considerando la forma de expresión política de estos dos grupos sunitas radicales -la yihad menor contra militares y civiles inocentes-, no es del todo erróneo definirlos como nihilistas, aunque en un sentido político.

Este deseo de destrucción viene dado por la negación hacia lo establecido: el sistema neoliberal-capitalista, nacido en Occidente. Como bien relata Hinkelammert (2001), este sistema es antiutópico porque, irónicamente, también niega la metafísica, en tanto -suponen- traería el infierno -tal como lo hicieron los soviéticos que quisieron imponer su sociedad perfecta comunista a costa de represión y millones de muertos-. Según el autor, el capitalismo tuvo una utopía: que, gracias a la mano invisible y reguladora del mercado, el egoísmo intrínseco de las personas sería guiado hacia el bien común. Al existir conciencia de sus limitaciones y de la realidad que creaba, con brutales desigualdades y exclusiones, el neoliberalismo niega esa utopía capitalista -y cualquier otra-. Así, evita el juicio crítico. Ahora se debe convivir con las desigualdades, porque son parte de la realidad y de la naturaleza humana. No existe alternativa o solución posible.

Dice Nietzsche (1981) que, en el contexto de crisis de sentido metafísico, “(...) para elevarse, luchando, de este caos a esta configuración surge una necesidad, hay que elegir: o perecer o imponerse. Una raza -o grupo- dominante solo puede desarrollarse en virtud de principios terribles y violentos" (p. 473). Esto es aplicable a la realidad de los yihadistas, quienes, al costo que sea, no están dispuestos a perecer frente al capitalismo, a pesar de que las opciones de que su ideología se imponga son nulas, al menos en los aspectos más radicales. Entonces, ¿por qué mantienen su postura? La respuesta está dada por el mesianismo político.

Todorov (2012) define mesianismo político como la imposición de una idea u orden social particular, visto como "paraíso terrenal" -fin metafísico- al que todos los individuos se deben subordinar. Para llegar a ese fin se justifica cualquier medio, incluso destruir a otros. Este mesianismo está presente en la ideología yihadista sunita, en donde ven en la sharia el proyecto político que traerá todas las bondades a la sociedad mundial, al cumplir, supuestamente, con los designios de Alá. Como dice Hinkelammert (1991) -que, si bien lo hace en relación al catolicismo, se puede extrapolar al islamismo radical-, en nombre de esa ley se acepta toda muerte. 
Marta de la Vega (2006) reflexiona, a raíz de su lectura sobre Nietzsche, que este asume que lo "verdadero" y el "bien" son lo mismo, por lo cual resultaría que mi verdad sería un bien. Esto podría derivar en que ciertos movimientos, como los yihadistas, merecen imponer su "verdad" al costo que sea, porque es el "bien".

En definitiva, el nihilismo pone en cuestión la racionalidad misma -ante el descubrimiento de que todo valor es producto de cierta voluntad de poder y no de una razón objetiva-, por lo cual hay una revalorización de lo irracional, de los instintos -considerados por Nietzsche como creadores, a diferencia de la razón, destructora-, así como del voluntarismo (Dannhauser, 1993; García, 2008; Nietzsche, 2013), en sí mesiánico. Aquí ya no existe "moral del deber por el deber, sino moral del deber por el querer" (García, 2008: 2). Un acto bueno sería tal si es que es favorable a ese fin (pseudo) metafísico dado por la voluntad de poder, sin importar el medio de acción usado.

Esa, digamos, irracionalidad a-moral (más bien inmoral) tiene directa relación con el mundo post Guerra Fría, que carente de alternativas al neoliberalismo, quedó huérfano de principios metafísicos. Lo anterior lleva a que resurjan estos movimientos fundamentalistas religiosos (Caro, 2002; Habermas, 2008), en busca desesperada de algún ideal. Pero este resulta ser un ideal que niega la realidad, y lo hace en nombre de un mundo suprasensible (Muñoz, 1994). Por tanto, es un ideal nihilista. Pero todas las religiones apelan a un mundo suprasensible. ¿Entonces, todas las religiones son nihilistas? Pues no. De hecho, la mayoría de los musulmanes, cristianos, judíos, etc., que actúan en la vida pública, lo hacen según sus valores morales y en base al contexto (realidad) en que se encuentran ${ }^{2}$. La religión (para bien o para mal) pretende ayudar a los feligreses en el "camino" del bien (el cumplimiento de los valores que promueve), pero con conciencia de que el "paraíso" de su religión jamás se podrá implementar en el mundo sensible. Hay conocimiento de que el ser humano es imperfecto, y de que nunca podrá ser perfecto, por tanto, las sociedades, en estricto rigor, tampoco, aunque siempre lucharán por acercarse a la perfección. La

2 Un ejemplo de ello es la encíclica Rerum Novarum de León XIII, de 1891, que fue escrita con el objetivo de actualizar el catolicismo a una nueva realidad social y política (modernidad). La Iglesia Católica, al igual que el judaísmo y la mayoría de los grupos religiosos y políticos del mundo musulmán, por lo general, con más o menos errores, busca que en este "mundo imperfecto" -de lo sensiblelas cosas fuesen lo más cercanas posibles al mundo suprasensible y perfecto (paraíso), teniendo como soporte los valores católicos. 
yihad sunita niega esa diferencia entre el mundo suprasensible y el mundo sensible, porque no creen en la imposibilidad de la perfección. De ahí que pretenda instaurar su "paraíso terrenal" (mesianismo político). Y, como este ideal es superior a cualquier otra cosa, ponen el fin por sobre los medios. De esa forma, paradojalmente, niega la moral de su religión -esencialmente no violentista- en nombre de esa misma moral.

Lo anterior supone, a los yihadistas nihilistas, negar cualquier otra religión y dar por sentado que todos están obligados a seguir los preceptos de la suya, ya que es la correcta.

Para Jacobo Muñoz (1994) la religión es nihilista, al menos en su versión más radical y fundamentalista, porque universaliza a todas las personas en torno a una moral, a una ley universal. Rechaza el hecho de que estos son diferentes (diversos) entre sí y tienen creencias y pensamientos distintos. Por consiguiente, niegan la realidad. Para ellos, toda realidad que demuestre lo contrario sobre su paraíso terrenal debe ser negada y destruida.

La yihad sunita tiene su fundamento en una paradoja. Se opone a un mundo sin metafísica, por lo cual busca imponer una, pero ellos mismos escapan de la lógica intrínseca a la metafísica, porque creen que están más allá del bien y el mal. Justifican sus asesinatos y matanzas, pero su rechazo es radical cuando proviene de "otros" (Occidente). Toda metafísica tiene una concepción de bien, expuesto en su ideal, así como de mal, que es todo lo diferente a ese ideal. A fin de cuentas, la yihad menor es pura irracionalidad in-moral nihilista.

Como punto de comparación con la yihad sunita global, se considerará el nihilismo alemán, siguiendo a Leo Strauss (2008), movimiento que tuvo como expresión más conocida el nazismo. Este, al igual que la yihad global, tenía el deseo de destruir la civilización occidental. También ambos comparten la oposición a lo que Strauss llamaba "sociedades abiertas", intrínsecas a las sociedades occidentales a las que consideran hedonistas y consumistas. Estas se destacan por ceñirse bajo una racionalidad instrumental y/o utilitaristas. Su contraparte eran las "sociedades cerradas", donde predominaban las virtudes nobles del verdadero sacrificio, del acto que no busca recompensa (el acto militar es máximo ejemplo de ello, por eso el componente militar es tan importante en el nihilismo alemán y en la yihad sunita global con los muyahidines). Si el mundo está destinado a satisfacer los placeres bajos, cualquier cosa era mejor para esos alemanes, incluso la nada. De ahí su motivación destructora (Strauss, 2008). En ese sentido, para los miembros de Al-Qaeda y del Estado Islámico, destruirlo todo, 
asesinar, incluso suicidarse en un acto terrorista, vendría a ser mejor que el neoliberalismo predominante. Por último, Strauss destaca que el nihilismo alemán sentía gran aversión por la civilización occidental, porque ellos no fueron parte de su origen. Cuando surgieron como nación, la civilización ya estaba creada. Esto con mayor razón afecta a los movimientos radicales sunitas, que ni siquiera forman parte de la civilización occidental y aún así deben adoptar sus sistemas (político, cultural, económico, etc.).

Pero también un número considerable de combatientes de Al-Qaeda y el Estado Islámico proviene de países occidentales, la mayoría de Europa. Según datos del Consejo de Seguridad de la ONU, en 2014 hubo veinticinco mil combatientes en alguno de los dos grupos, aproximadamente cinco mil provenían del Viejo Continente (Sancha, 2015). Por lo general, los occidentales que se suman a estos movimientos yihadistas son musulmanes de segunda o tercera generación, nacidos en Europa (Chamy, 2014). La razón de ello es que estos se sienten discriminados en esos países por su origen. Se sienten estigmatizados y decepcionados de Occidente (Chamy, 2014; Sohr, 2015), por lo cual recurren a la Umma, que sirve como espacio de acogida, a la vez que les da un ideal por el cual vivir y luchar (Sohr, 2015).
5. Perfil de los líderes

Y DISCURSO POLÍTICO:

EL ELITISMO DEL

MOVIMIENTO RADICAL SUNITA

Antes del análisis de los discursos de cada uno de los líderes, a modo de introducción repasaremos brevemente sus biografías, a fin de dar cuenta del componente más o menos popular -y/o elitista- de cada uno de sus liderazgos. Primero se verá la biografía de Bin Laden, luego la de al-Zawahiri y, por último, la de al-Baghdadi.

\subsection{Osama Bin Laden}

Como relata Elaine Landau (2001) y la biografía escrita por Cidob (2011), Osama Bin Laden nació en 1957 en Arabia Saudita. Hijo de Mohammed Bin Laden, multimillonario, dueño de "Bin Laden Construction Corporation", la principal constructora de Medio Oriente. Se dice que tuvo una vida profusamente religiosa, lo cual pudo influir en su hijo Osama (Landau, 2011). Gran parte del éxito familiar estuvo marcado por su cercanía con el régimen saudí, a quienes les llegó a costear los gastos de gobierno en un contexto de crisis económica, lo cual le valió obtener el monopolio de la construcción del país. Sin duda este éxito le dio a Osama acceso a una de las más grandes fortunas e importantes con- 
tactos en Medio Oriente (CIDOB, 2011).

Sus estudios secundarios los realizó en uno de los colegios más elitistas de Egipto, el Victoria College de Alejandría. Además, tuvo la oportunidad de viajar muchas veces a Europa, donde recibió formación especializada y aprendió inglés. Se inició en la doctrina de la fe en un seminario coránico de Jeddah antes de estudiar Ingeniería, Gestión de Empresas y Teología islámica en la Universidad Rey Abdulaziz de Jeddah, Arabia Saudita; al tiempo que participó en la administración del imperio empresarial familiar (CIDOB, 2011).

Conocidas fueron sus andanzas juveniles, con mujeres y alcohol, en sus viajes por Europa. Aunque ello habría cambiado paulatinamente cuando trabajó en la restauración de dos mezquitas, formando amistades con fundamentalistas, a lo que se sumó el contexto de guerra contra Israel en 1973 (Landau, 2001). Con la invasión soviética a Afganistán, estos sentimientos fundamentalistas se consolidaron, siendo uno de los más importantes participantes en la exitosa resistencia afgana (CIDOB, 2011). En esa guerra afloró su postura antiimperialista, primero contra la Unión Soviética y luego contra Estados Unidos, como ya se vio. Por lo mismo, cuando Arabia Saudita tuvo el apoyo estadounidense en la primera guerra del golfo contra el
Irak de Hussein, Bin Laden hizo lo posible por evitarlo. Pero el régimen saudí no veía otra forma de ganar la guerra y aceptó la ayuda de Washington. Para Bin Laden el poder de la fe musulmana era suficiente. Todo esto desencadenó un conflicto entre ambas partes que terminó con Osama exiliado en Sudán, que en ese entonces tenía un gobierno fundamentalista.

Pero Bin Laden tuvo el apoyo de muchos árabes que desconfiaban de Estados Unidos, lo cual facilitó la tarea de reclutamiento de Al-Qaeda cuando se consolidó como grupo yihadista que busca instaurar el Estado Islámico global. Tras ser el responsable de una serie de atentados en Europa, Estados Unidos, Medio Oriente y África, comenzó a ser uno de los hombres más buscados del mundo, lo cual fue un problema para Sudán que, tras fuertes presiones de los países occidentales, tuvo que pedirle que saliera del país, eligiendo como destino Afganistán, país dominado en ese entonces (1996) por el Talibán, grupo fundamentalista radical sunita (Landau, 2001). Nunca se supo cuándo dejó Afganistán. El Régimen Talibán y Estados Unidos tuvieron un fuerte impasse diplomático por este motivo, pero ni siquiera después del atentado del World Trade Center cedieron a las presiones de Washington. Finalmente, murió asesinado por fuerzas estadounidense en Pakistán, 
donde vivía en una lujosa mansión (Bernabé, 2011).

Hay quienes plantean que en un comienzo Osama Bin Laden era un islamista moderado, que se radicalizó en el wahabarismo sunita en los ochenta, influenciado por alZawahirí (Pardo, 2011). Lo cierto es que su carisma e inteligencia militar eran incuestionables, además de su poder económico, todo lo cual le permitió crear y liderar Al-Qaeda. Su carácter mesiánico, como líder, es evidente, aunque más marcado es el mesianismo político religioso de su pensamiento, demostrado en la creencia de que Arabia Saudita podía vencer a Irak en la primera guerra del golfo solo mediante el poder de la fe, libre de ayuda extranjera.

\subsection{Aymán al-Zawabiri}

Su familia era parte de la élite de su país, Egipto. De profesión es médico cirujano ocular. Nació en El Cairo, el 19 de junio de 1951. Se involucró en el islam político cuando estaba en el colegio. Fue arrestado a los 15 años por ser miembro de la Hermandad Musulmana (BBC News, 2011). Es probable que en ese entonces comenzara su proceso de radicalización.

Se unió a la Yihad Islámica Egipcia cuando se fundó, en 1973. Cumplió condena en prisión por su participación en el asesinato del presidente egipcio Anwar Sadat, en 1981. Este había enfurecido a los extremistas islamistas al firmar un acuerdo de paz con Israel. Fue absuelto por el homicidio de Sadat, aunque cumplió condena de tres años por posesión ilegal de armas. Hay quienes dicen que, por las torturas sufridas en la cárcel, al-Zawahirí se radicalizó aún más (BBC News, 2011).

En la década de los noventa asumió como líder de la Yihad Islámica Egipcia, con el objetivo de derrocar al gobierno civil egipcio. Esa guerra civil significó la muerte de 1.200 egipcios (BBC News, 2011).

Al-Zawahiri es considerado el principal ideólogo de Al-Qaeda -por lo que su mesianismo personal pareciera ser menos fuerte que el mesianismo político- y hay quienes mencionan que es más radical y violento que Bin Laden (Pardo, 2011). Otra diferencia es que su principal preocupación era la ampliación de la organización hacia otros sectores geográficos. De hecho, lo amplió hacia Asia y África cuando asumió como líder. Osama Bin Laden era más cauteloso al respecto, queriendo asegurar, antes que nada, el orden y lealtad de todas las células.

\subsection{Abu Bakr al-Baghdadi}

La información que se posee del líder del Estado Islámico es bastante poca y no del todo confiable. Se afirma que nació en 1971 en Samarra, Irak (McCoy, 2014). Se le 
menciona como hombre de familia religiosa. Algunos de sus hermanos y tíos habrían sido predicadores y profesores de lengua árabe, retórica y de lógica, mientras otros fueron altos mandos militares en la Irak de Saddam Hussein (López, 2015).

También se dice que tuvo un doctorado en Estudios Islámicos en la Universidad Islámica de Bagdad. Sí es seguro que estuvo prisionero, en 2004, en Camp Bucca, al sur de Irak, por fuerzas estadounidenses. Se cree que ahí conoció a muchos islamistas radicales (McCoy, 2014) y adoptó una posición más extremista por la tortura a la que fue sometido por el ejército estadounidense (BBC News, 2015). Luego de esta experiencia entró al Estado Islámico, cuando la agrupación todavía era parte de Al-Qaeda (McCoy, 2014).

En cuanto a su liderazgo, se ha mostrado mucho más abierto y menos elitista -tal vez, resultado de su origen más humilde-, aunque sí mesiánico y personalista, en tanto se declaró como el nuevo califa del islam, en su primer discurso, donde dijo: "soy el wali (líder) designado para dirigirlos, pero no soy mejor que vosotros. Si piensas que tengo razón, ayúdame. Si crees que estoy equivocado, aconséjame y guíame en el buen camino" (AFP, 2014). No obstante, su nivel de estudio da cuenta de un fuerte elitismo.

\subsection{Análisis de discursos}

Se analizaron ocho discursos, de los cuales dos corresponden a $\mathrm{Abu}$ Bakr al-Baghdadi, tres a Aymán al-Zawahirí y tres a Osama Bin Laden. Todos estos fueron analizados por Word Cloud, programa que cuenta el número de palabras que más se repiten, a partir del cual se determinará, preliminarmente, si existen referencias fundamentalistas, antiimperialistas y/o nihilistas. Referencias políticas se asociarán con nihilismo. Esto porque si hay un espacio central de lo político en sus discursos, a niveles cercanos o similares a las insinuaciones religiosas y antiimperialistas, significa que los objetivos políticos son primarios o están a la par con los otros, lo cual significaría que sus objetivos políticos, nihilistas como pudimos ver en la parte teórica, son suficientes para definir los casos de la yihad sunita global, como Al-Qaeda y el Estado Islámico, de nihilistas político-mesiánicos (tanto como antiimperialistas y fundamentalistas religiosos). Palabras que apunten a temas regionales, países o líderes mundiales en específico, se considerarán antiimperialistas. Si se habla de Dios, Alá o musulmanes -como comunidad religiosa- serán encasilladas como fundamentalistas religiosas. Desde luego este análisis no será concluyente sobre el carácter nihilista de la yihad sunita -considerando que antiimperialis- 
mo, fundamentalismo religioso y nihilismo no son excluyentes entre sí-, pero sí considera los énfasis discursivos importantes porque son los motivantes de la acción yihadista. Primero se mencionarán los resultados generales, las palabras más repetidas en los discursos de cada líder, para luego compararlos y dar algunas conclusiones generales.

Sobre el líder del Estado Islámico, Abu Bakr al-Baghdadi, el primer discurso es de un texto titulado "Un mensaje a los muyahidines y la comunidad musulmana en el mes de Ramadán”, lanzado el primero de julio del 2014 por la IS' al-Furqan Media Foundation' (SITE, 2014). El segundo discurso que se analizará, también proveniente de ahí, es una grabación tomada en la mezquita de Mosul del viernes 4 de julio del 2014. Esta fue transcrita desde la página web de YouTube. En estos dos discursos las palabras que más se repetían estaban relacionadas con "Alá", la "comunidad musulmana" y la religión en general. Llegaban a sumar en torno a un $10 \%$ o $15 \%$ del total de palabras. Ello demuestra una tendencia más fuerte hacia el fundamentalismo religioso. Aun así, no se puede dejar de considerar que las palabras "terrorismo", "Estado" y "yihad" fueron mencionadas entre un 3\% y un $5 \%$. Esas tres palabras esconden un componente político y se repiten más que cualquier otra palabra referente a antiimperialismo.
Sobre Al-Zawahiri, el primer discurso es una transcripción de un mensaje de video -sacado de BBC News- del 16 de noviembre del 2005, en que alabó los atentados del 7 de julio en Londres. En el segundo se refiere a un atentado en Pakistán, donde murieron 18 personas (CNN International, 2006). El tercero es un discurso donde aborda la situación en Pakistán e Irak (BBC News, 2006). Las palabras que más se repitieron en estos discursos fueron "cruzados", "Bush", "Blair" y "Pakistán”, entre otros. Referencias antiimperialistas como esas representaban en torno al 10\% del total de palabras en cada discurso, siendo mayoría, salvo en el segundo discurso donde llegaba al 5\%, teniendo muchas referencias religiosas, que superaban el $5 \%$ ("musulmanes", "Dios"). En menor medida había referencia a "guerra" y "terrorismo". En consecuencia, los discursos de Al-Zawahiri muestran una tendencia antiimperialista marcada, con cierto componente del fundamentalismo religioso. Prácticamente no hay referencias políticas o nihilistas.

De Osama Bin Laden los discursos escogidos fueron: 1) la declaración de yihad contra Estados Unidos, de 1996 (FBIS, 2004); 2) el discurso "América aterrorizada", dado después de los atentados del 11 de septiembre de 2001, y 3) una declaración de 2008 donde critica la intervención de los países euro- 
peos en Afganistán (CFR, 2008). En general, las referencias del primer y tercer discurso muestran una tendencia más religiosa (con palabras como "Alá", "Papa", "Dios", "santa" y "musulmanes"), más claro en el primero que en el tercero, llegando a superar el $5 \%$-en el tercero está bajo ese porcentaje-. Hay referencias al antiimperialismo con palabras como "insultante", "Estados Unidos”, "europeo" y "país", aunque en todos los discursos están bajo el $5 \%$, salvo en el segundo, que supera, en forma leve, ese porcentaje. Las referencias políticas son menores, prácticamente nulas en el segundo discurso, aunque presentes en el primero y en el tercero, con palabras como "lucha" o "régimen", aunque no superan el $2 \%$ del texto.

Sobre el análisis de discurso se puede concluir que las tendencias declaratorias de Abu Bakr al-Baghdadi y de Osama Bin Laden son más proclives al fundamentalismo religioso, mientras que en Al-Zawahirí hay mayor referencia al antiimperialismo. Es interesante notar este punto, porque no pareciera ser casualidad que Al-Qaeda haya tenido cierto bajón respecto del Estado Islámico, justo en el momento en que Bin Laden murió. Por un lado, se puede aducir que eso se debe al carisma de los líderes, muy alto en el caso de Osama y de al-Baghdadi, pero también se puede decir que hay un peso en cuanto al tema religioso, ya que da un elemento de identidad y comunidad mucho más poderoso que el puro y simple odio hacia una civilización. Por otro lado, las referencias políticas son casi nulas, salvo en el caso del líder del EI. Esto hace suponer que el nihilismo político-mesiánico es algo que se da exclusivamente en la forma, pero no es parte sustantiva del ideario de la yihad sunita, lo cual significa que la radicalización es únicamente producto de la visión antiimperialista y fundamentalista. De todas formas, es una conclusión preliminar, ya que faltan estudios sobre la materia, en la medida que es necesario indagar más en otro tipo de investigaciones empíricas, en especial porque, como se dijo en la introducción, el antiimperialismo, el nihilismo mesiánico y el fundamentalismo religioso/ islamismo, son elementos que se interrelacionan entre sí, siendo este último el que tiene preponderancia sobre los demás, ya que es el factor de mayor unidad dentro de la yihad (umma o comunidad); mientras que el antiimperialismo es un elemento diferenciador (con los otros, que son los occidentales). Dentro de ese entramado, el nihilismo políticomesiánico, o más bien los objetivos de poder, son percibidos como un medio, no como el fin, y no es la razón legitimadora, por lo cual es menos relevante considerarlo dentro de los respectivos discursos. 


\section{Conclusiones}

En este trabajo se intentó demostrar el carácter político-nihilista de la yihad sunita, teórica y empíricamente, como una (posible) tercera forma de entender este fenómeno. Las otras dos serían: fundamentalismo/islamismo y antiimperialismo o antioccidentalismo (con alto grado de antisemitismo). Como se mencionó, estos conceptos no son, necesariamente, excluyentes entre sí, de hecho, al menos teóricamente, se pueden considerar complementarios. Difícilmente la yihad sunita será nihilista sin considerar su antiimperialismo -ese deseo de destruir la civilización occidental y todo rastro de la misma- y su antisemitismo -expresado en su rechazo a Israel-. A a su vez, este no estaría presente si no fuera por el carácter fundamentalista religioso e islamista.

No obstante, en cuanto a la comprobación empírica de la presencia de nihilismo político, enfocándonos en el discurso de los principales líderes $3 / 4$ que no expresa otra cosa que la ideología que motiva a la acción política $3 / 4$, de los dos casos en particular que se analizaron (Estado Islámico y Al-Qaeda), los resultados mostraron una mayor tendencia al fundamentalismo religioso y al antiimperialismo que al nihilismo político-mesiánico. Si bien el componente político sí está presente en los discursos -en espe- cial en los dados por al-Baghdadi-, su presencia es menor.

Por ello es que, por mucho que teóricamente podamos decir que sí existe un componente nihilista político-mesiánico, no es algo que en este trabajo se haya comprobado empíricamente, por lo que la hipótesis es desestimada.

También se puede concluir que el personalismo forma parte de los liderazgos de Bin Laden y al-Baghdadi, mas no en al-Zawahiri. Para el primero y el tercero pareciera ser más fuerte, en especial el líder del Estado Islámico quien se autodesignó califa. Además, al-Zawahiri pareciera tener su foco más centrado en la ideología del movimiento que en el culto a su persona.

En sus discursos, tanto Bin Laden como al-Baghdadi han privilegiado lo religioso -que tiene cierto elemento unificador porque destacan la umma como comunidad, sin por ello dejar de ser confrontacional-, por sobre lo antiimperialista -abiertamente confrontacional-, a diferencia de alZawahiri. Es interesante notar esto, porque al-Zawahiri es considerado el principal ideólogo de Al-Qaeda, así que es posible que la ideología misma privilegie la confrontación y, por ello, quizá la destrucción. Aunque esto no es más que una conjetura, ya que el hecho de que el discurso sea antiimperialista, en sí no lo vuelve nihilista. 
Lo que sí comparten los tres es el carácter elitista, lo cual queda demostrado en su nivel de estudios (todos tienen posgrados o estudios en universidades prestigiosas). Por otro lado, la organización de estos movimientos es muy jerarquizada, lo que los lleva a estar a la cabeza de estos. Lo anterior es más claro en el EI, ya que hay una organización muy centralizada en al-Baghdadi, mientras que en Al-Qaeda la estructura es descentralizada, lo cual permite que existan líderes regionales. Pero, pese a ello, el liderazgo de al-Baghdadi, al ser la cabeza visible, pareciera ser más cercana -quizá motivado por sus orígenes humildes y/o simplemente como parte de su estrategia política-, lo que refuerza con sus alocuciones, dando la sensación de una relación más directa con los militantes del movimiento, que en parte se debe a la centralización del poder. Bajo esa premisa, Al-Qaeda sería más lejano, en parte, por la descentralización del poder (la relación es más indirecta con los militantes).

\section{BIBLIOGRAFÍA}

Aguirre, Á. (2011). Análisis del accionar terrorista del grupo Al- Qaeda a la luz de la ideología salafista. Período 2001-2008. Bogotá DC: Universidad Colegio Mayor de Nuestra Señora del Rosario.

Ahmed, R. (2012). La reconducción estratégica de Al-Qaeda: ¿̇del liderazgo de Osama bin Laden a la dimensión masiva-popular? Civilizar, 22(12), pp. 111-128.

AFP (6 de julio de 2014). ABC.es Internacional. Recuperado el 5 de Junio de 2015, de abc.es: http:/www.abc.es/ internacional/20140706/rc-bakr-bagdadi-califa-yihadista-201407060006. html

Alonso, R. (2015). El terrorismo yihadista: una amenaza híbrida. Cuadernos de pensamiento político, pp. 61-80.

Barcelona centre for international affairs CIDOB (mayo de 2011). Recuperado el 31 de mayo de 2015, de: http:// www.cidob.org/: http://www.cidob. org/biografias_lideres_politicos/asia/ arabia_saudi/osama_bin_laden

BBC News (15 de mayo de 2015). $B B C$ News. Recuperado el 6 de junio de 2015, de bbc.com: http:// www.bbc.com/news/world-middleeast-27801676

BBC News (16 de junio de 2011). $B B C$ News. Recuperado el 31 de mayo de 2015, de bbc.com: http:// www.bbc.com/news/world-middleeast-13789286

BBC News (29 de abril de 2006). Recuperado el 31 de mayo de 2015, de news. bbc.co.uk: http://news.bbc.co.uk/2/hi/ middle_east/4957292.stm.

BBC News (16 de noviembre de 2005). Recuperado el 2015 de mayo de 31, de news.bbc.co.uk: http://news.bbc. co.uk/2/hi/middle_east/4443364.stm

Bernabé, M. (2 de mayo de 2011). El Mundo. Recuperado el 31 de mayo de 2015, de elmundo.es: http://www. elmundo.es/elmundo/2011/05/02/ internacional/1304309519.html

Bofill, P. (2011). Algunas claves de la yihad global. Tiempo de paz, (101), pp. 73-78.

Campuzano, F. (2007). De la Guerra Fría al choque de civilizaciones: nacionalismo y milenarismo en la obra de Samuel P. Huntington. Nueva Época, XX(54), pp. 153-175. 
Caro, I. (2013). Temas y procesos del sistema internacional. En Bello, D. (ed.), Manual de Relaciones Internacionales: Herramientas para la comprensión de la disciplina, pp. 167-207. Santiago, Chile: RIL Editores.

Caro, I. (2002). La reemergencia de fundamentalismos islámicos y judíos: El escenario internacional, el Medio Oriente y América Latina. Ciencias Sociales y Religión/Ciências Sociais e Religião, IV(4), pp. 167-186.

Castells, M. (1999). La era de la información: Economía, sociedad y cultura (Vol. II). México DF: Siglo Veintiuno . CNN International (30 de enero de 2006). Recuperado el 31 de mayo de 2015, de edition.cnn.com: edition.cnn. com/2006/WORLD/asiapcf/01/30/ zawahiri.transcript/

Colombo, V. (2012). Califa, sultán, emir. Ecclesia, (2), pp. 233-235.

Council Foreign Relations (19 de marzo de 2008). Recuperado el 31 de mayo de 2015, de www.cfr.org: http://www. cfr.org/terrorism/osama-bin-ladensstatement-march-2008/p15783?bre adcrumb $=\% 2$ Fissue $\% 2$ F $135 \% 2$ Fte rrorism

Chamy, C.H. (23 de agosto de 2014). $B B C$ Mundo. Recuperado el 31 de mayo de 2015, de http://www.bbc. co.uk/: http://www.bbc.co.uk/mundo/ noticias/2014/08/140822_yihadistas_ occidente_europa_como_llegan_ch

Dannhauser, W. (1993). Fredrich Nietzsche (1844-1900). En Strauss, L. \& Cropsey, J., Historia de la filosofía política, pp. 779-798. México DF: Fondo de Cultura Económica.

De la Vega, M. (2006). Paradojas del nihilismo y la voluntad de poder: Actualidad del pensamiento de Nietzsche. Revista Philosophica, pp. 51-63.

EFE (19 de mayo de 2015). La Vanguardia Internacional. Recuperado el 17 de junio de 2015, de lavanguardia.com: http://www.lavanguardia.com/internacional/20150519/54431735335/ siria-e-iran-escenifican-su-alianzacon-viaje-a-damasco-de-asesor-dejamenei.html

FBIS (2004). Compilation of Usama Bin Ladin. Stataments 1994 - january 2004. FBIS. FBIS Report.

Fernández, L. (2007). Las raíces del terrorismo: De la psicología de la multicausalidad a la psicología de la ignorancia. Psicología Conductual, XV(1), pp. 113-128.

Frankl, V. (1979). El hombre en busca de sentido. Barcelona: Herder.

Ferrando, M.G. (2005). Globalización, valores sociales y choque de civilizaciones. Revista Internacional de Sociología, (42), pp. 127-150.

García, A. (2008). Nietzsche: La negación de los valores y el nihilismo. A parte Rei. Revista de Filosofía.

Gil, P. (2010). Conceptualización del Islamismo. España: Instituto Universitario General Gutiérrez Mellado.

Glucksman, A. (2002). El fantasma del nihilismo. Claves de razón práctica, (125), pp. 20-27.

Gutiérrez, C. (2009). Sobre el concepto de yihad. Athena Intelligence Journal, IV(1), pp. 189-214.

Habermas, J. (2008). El resurgimiento de la religión, ¿un reto para la autocomprensión de la modernidad? Diánoia, LIII(60), pp. 3-20.

Hinkelammert, F. (2001). El nibilismo al desnudo: Los tiempos de la globalización. Santiago: LOM.

Hinkelammert, F. (1991). La fe de Abraham y el edipo occidental. San José: DEI.

Huntington, S. (2005). El choque de civilizaciones y la reconfiguración del orden mundial. Barcelona: Paidós.

Ibáñez, L. (2007). Algunas claves psicosociales para el análisis y la explicación de los fenómenos terroristas. Athena Intelligence, II(3), pp. 38-57.

International Crisis Group. (2005). Understanding Islamism. 
Izquierdo, F. (2011). Islam político en el siglo XXI. CIDOB d'Afers Internacionals, (93-94), pp. 11-32.

Landau, E. (2001). Osama Bin Laden: El terrorismo del Siglo XXI. (G. D. Masso, Trad.) Barcelona: Planeta.

León, M.U. (2008). ¿Hacia una civilización universal? Una crítica del "choque de civilizaciones" de Huntington. Estudios de Deusto, LVI(2), pp. 105-133.

Lewis, B. (1990). The roots of muslim rage. The Atlantic Monthly, pp. 4760.

López, I. (1 de marzo de 2015). Excelsior. Recuperado el 6 de Junio de 2015, de excelsior.com.mx: http://www.excelsior.com.mx/global/2015/03/01/1010914

Maalouf, A. (2005). Identidades asesinas. Madrid: Alianza.

McCoy, T. (11 de Junio de 2014). The Washington Post. Recuperado el 5 de junio de 2015, de washingtonpost.com: http://www.washingtonpost.com/news/morning-mix/ wp/2014/06/11/how-isis-leader-abubakr-al-baghdadi-became-the-worldsmost-powerful-jihadi-leader/

Moyano, M., Tabernero, M. \& Trujillo, H. (s.f.). Estudios Militares. Recuperado el 8 de junio de 2015, de: http://estudiosmilitares.es/: http://estudiosmilitares.es/comunicaciones/Manuel\%20 Moyano, \% 20M\% C2\% AA \% 20 del $\% 20$ Carmen $\% 20$ Tabernero $\% 20$ y\%20Humberto\%20Trujillo.pdf

Muñoz, J. (1994). Nihilismo y crítica de la religión en Nietzsche. En Fraijó, M., Filosofía de la religión: estudios y textos, pp. 345-367. Madrid: Trotta.

Nadal, M. (13 de abril de 2015). El Orden Mundial en el siglo XXI. Recuperado el 7 de junio de 2015, de: http:// elordenmundial.com/: http://elordenmundial.com/seguridad/estadoislamico-realmente-un-estado/
Nietzsche, F. (1981). La voluntad de poderío (segunda ed., 2000). Santiago: EDAF.

Nietzsche, F. (1972). Más allá del bien y del mal (tercera ed., 2013). Madrid: Alianza Editorial.

Pardo, P. (2 de mayo de 2011). El Mundo. Recuperado el 31 de mayo de 2015, de elmundo.es: http://www.elmundo. es/elmundo/2011/05/02/internacional/1304326110.html

Pérez, J. (24 de agosto de 2014). El Orden Mundial en el siglo XXI. Recuperado el 7 de junio de 2015, de elordenmundial.com: http://elordenmundial. com/regiones/oriente-medio/estadoislamico-el-nuevo-enemigo/

Petras, J. (2004). Imperialismo y Antiimperialismo. Laberinto, (15).

Priego, A. (2014). El Estado Islámico: ¿Segunda parte de Al-Qaeda o algo nuevo? Razón y Fe (270), pp. 491-504.

Quesada, R. (2010). Biblioteca Virtual Miguel de Cervantes. Recuperado el 25 de abril de 2015, de http://www. cervantesvirtual.com/: http://www. cervantesvirtual.com/obra-visor/ el-antiimperialismo-a-la-luz-de-losheroes-del-98-marti-hostos-betancesy-sandino/html/af829ae8-6677-4f53b570-1c31ec25c416_2.html

Retóricas (octubre de 2001). Recuperado el 2015 de mayo de 31, de retoricas.com: http://www.retoricas. com/2010/05/discurso-de-bin-ladenlos-estados.html

Romero, A. \& Troyano, Y. (2013). Las raíces socioestructurales del terrorismo fundamentalista islámico. Convergencia, XX(62), pp. 181-198.

Serrano, J. P. (2003). El paradigma del choque de civilizaciones: Fundamentos científicos y elementos ideológicos. Revista Escuela de Historia, I(2), pp. 1-11.

Sancha, N. (2 de abril de 2015). El País Internacional. Recuperado el 31 de mayo de 2015, de internacional.elpais.com: http://internacional.elpais. 
com/internacional/2015/04/02/actualidad/1427982406_915115.html

Sanz, J. C. (22 de mayo de 2015). El País Internacional. Recuperado el 7 de junio de 2015, de http://internacional.elpais.com/: http://internacional. elpais.com/internacional/2015/05/22/ actualidad/1432284707_896932. html

SITE (1 de julio de 2014). SITE: Monitoring service jihadist threat. Recuperado el 31 de mayo de 2015, de news. siteintelgroup.com: https://news. siteintelgroup.com/Jihadist-News/ islamic-state-leader-abu-bakr-albaghdadi-encourages-emigrationworldwide-action.html

Sohr, R. (2015). El Frankestein yihadista. Mensaje, (637), pp. 11-13.

Strauss, L. (2008). El Nihilismo Alemán. En Esposito, R. G., Nihilismo $y$ Política, pp. 125-152. Buenos Aires: Manantial.

Todorov, T. (2012). Los enemigos intimos de la democracia. (N. Sobregués, trad.). Barcelona: Galaxia Gutenberg.

Trujillo, H., Alonso, F., Jiménez-Ferrer, C., \& Ramírez, J. (2009). Evidencias de manipulación psicológica coercitiva en terroristas islamistas. Athena Assessment (4).

Trujillo, H., González-Cabrera, J., León, C., Valenzuela, C. \& Moyano, M. (2006). De la agresividad a la violencia terrorista: Historia de una patología psicosocial previsible (Parte I). Psicología Conductual, XIV(2), pp. 273-288.

Trujillo, H.; González-Cabrera, J.; León, C.; Valenzuela, C. \& Moyano, M. (2006). De la agresividad a la violencia terrorista: Historia de una patología psicosocial previsible (Parte II). Psicología Conductual, XIV(2), pp. 289-303.

Valenzuela, E. (2012). Terrorismo y Fundamentalismo. Revista Chilena de Economía y Sociedad, V(1-2), pp. 41-51.
Valenzuela, C. (2008). El quiebre de la República de Weimar en Alemania (1918-1933) y su expresión en la novela La montaña mágica de Thomas Mann. Universidad de Chile, Santiago.

Wallerstein, I. (2003). La decadencia del poder estadounidense: Estados Unidos en un mundo caótico. Santiago: LOM.

Ward, T. (2002). Los posibles caminos de Nietzsche en el modernismo. Nueva revista de filología hispánica, pp. 489-515.

YouTube (12 de julio de 2014). Recuperado el 31 de mayo de 2015, de www. youtube.com: https://www.youtube. $\mathrm{com} /$ watch?v=PxJSm7XwxqA

Zarrouk, M. (2011). Orígenes del terrorismo global: Una propuesta de análisis. Revista de Relaciones Internacionales, estrategia y seguridad, VI(1), pp. 13-46. 